\title{
UNA MIRADA A LA ANESTESIOLOGÍA DESDE EL HOSPITAL DE SAN JOSÉ RECUENTO HISTÓRICO
}

Carlos Castellanos Ch. MD*

Para cualquiera que desee recorrer nuestra historia, encontrará que el Hospital de San José (Figura 1) está muy vinculado a la historia de la anestesia y de la medicina en Colombia. Fue fundado en 1902 y el grupo de fundadores eran casi todos egresados de la Universidad Nacional, especializados en universidades europeas, en especial en Paris, luego regresaron a Bogotá y constituyeron la Sociedad de Cirugía de Bogotá (Figura 2).

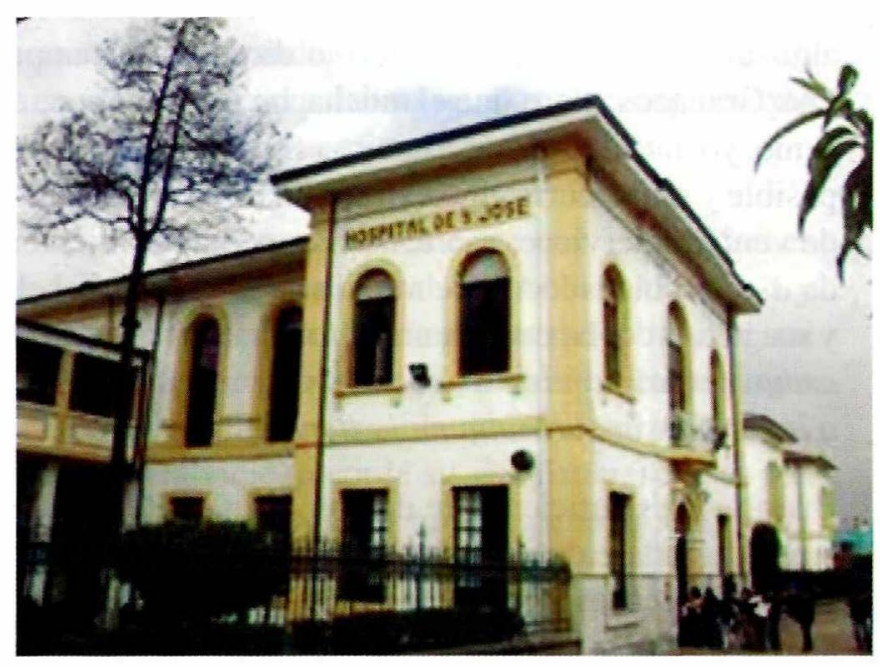

Figura I. Hospital de San José de Bogotá DC.

Para la época 1903 el doctor Isaac Rodríguez (Figura 3) en la Casa de Salud del Campito era el cloroformista y a la vez un facultativo del arte y ciencia de la anestesia según palabras del doctor Hipólito Machado

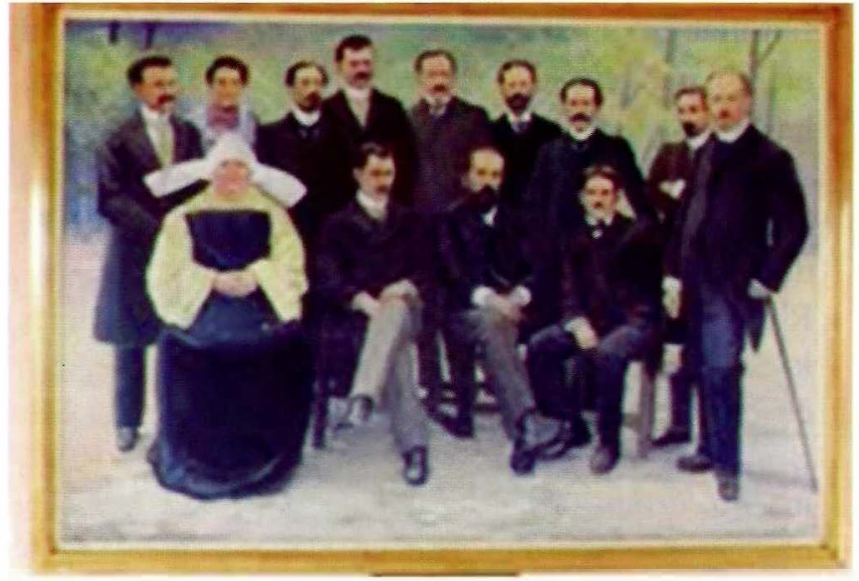

Figura 2. Los Fundadores de la Sociedad de Cirugía de Bogotá en la casa de salud El Campito de San José.

(Figura 4) en su informe a la asamblea de la Sociedad de Cirugía en su primer año de funcionamiento (19021903). El doctor Juan Evangelista Manrique (Figura 5) frente a cuestionamientos de la utilización de la anestesia informa a dicha sociedad "Un año de trabajo ha probado que nuestro clima no es inadecuado como se creyó para la práctica de la cirugía y la altura en la que vivimos no es una contraindicación para la anestesia general". En 1905 el doctor Lisandro Leyva Pereira (Figura 6) realiza la primera anestesia raquídea en el hospital; el mismo médico introdujo la anestesia general con cloroformo, éter, balsoformo y avertina. El doctor Andrés Bermúdez, su sucesor (1930-1931), solicitó una máquina con gases y se preparó al interno

* Miembro de la Sociedad de Cirugía de Bogotá. Profesor titular de Anestesiología, Fundación Universitaria de Ciencias de la Salud. Bogotá DC, Colombia. 
Rogelio Salcedo en la Clínica de Marly para su manejo, lo cual resultó frustrado pues el equipo se perdió en Buenaventura en 1931, siendo jefe de anestesia el ortopedista y cirujano doctor Manuel Bernal.

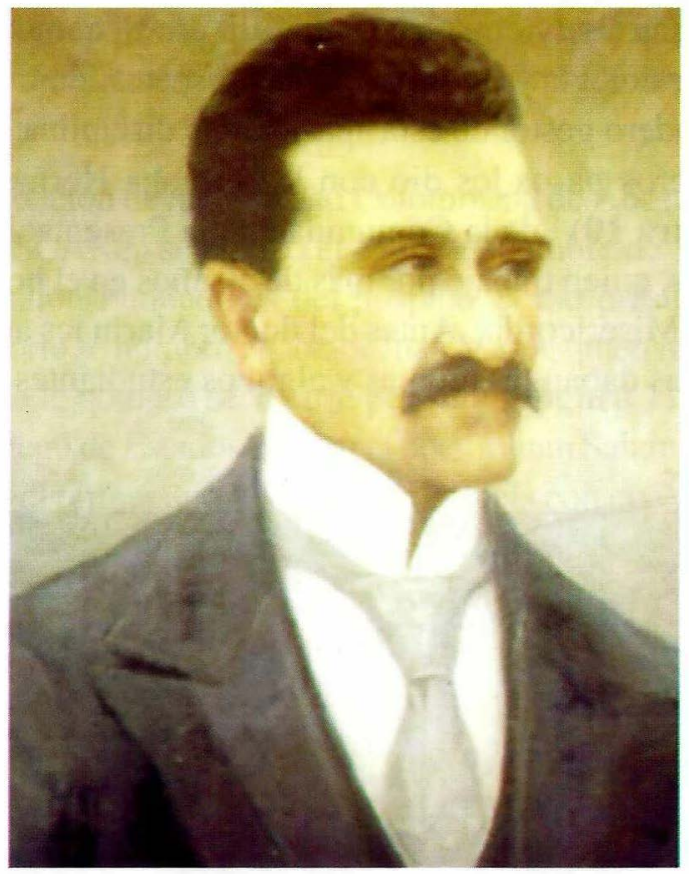

Figura 3. Dr. Isaac Rodriguez.

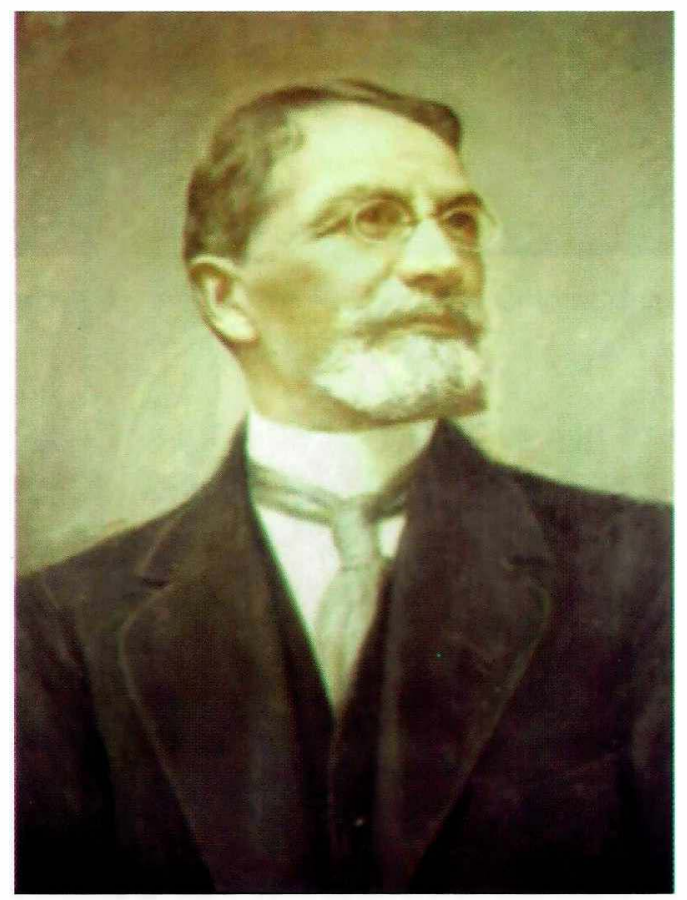

Figura 4. Dr. Hipólito Machado .

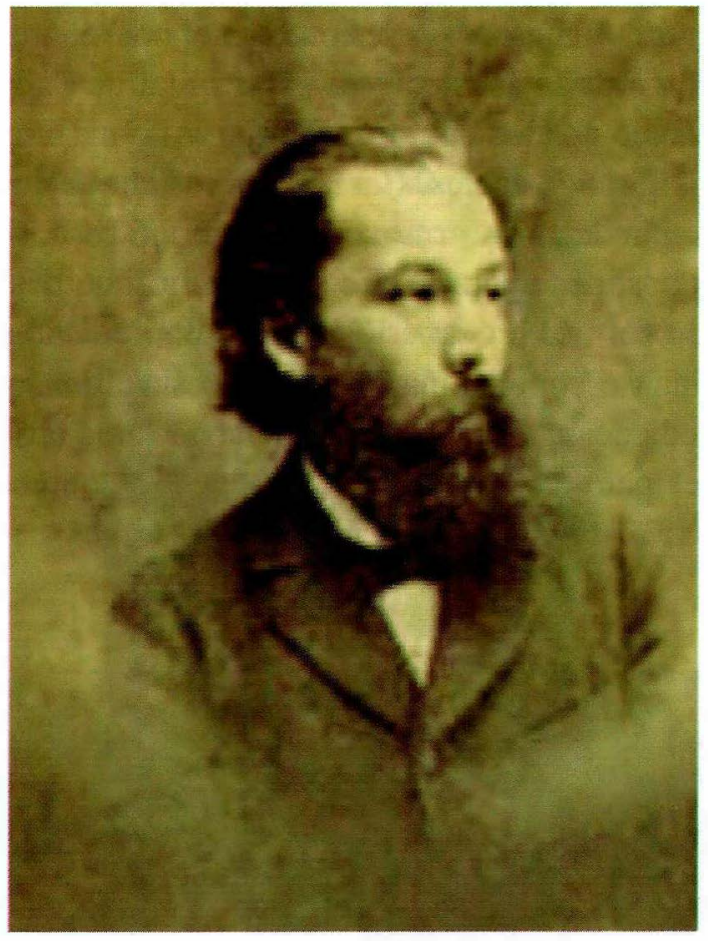

Figura 5. Dr. Juan Evangelista Manrique

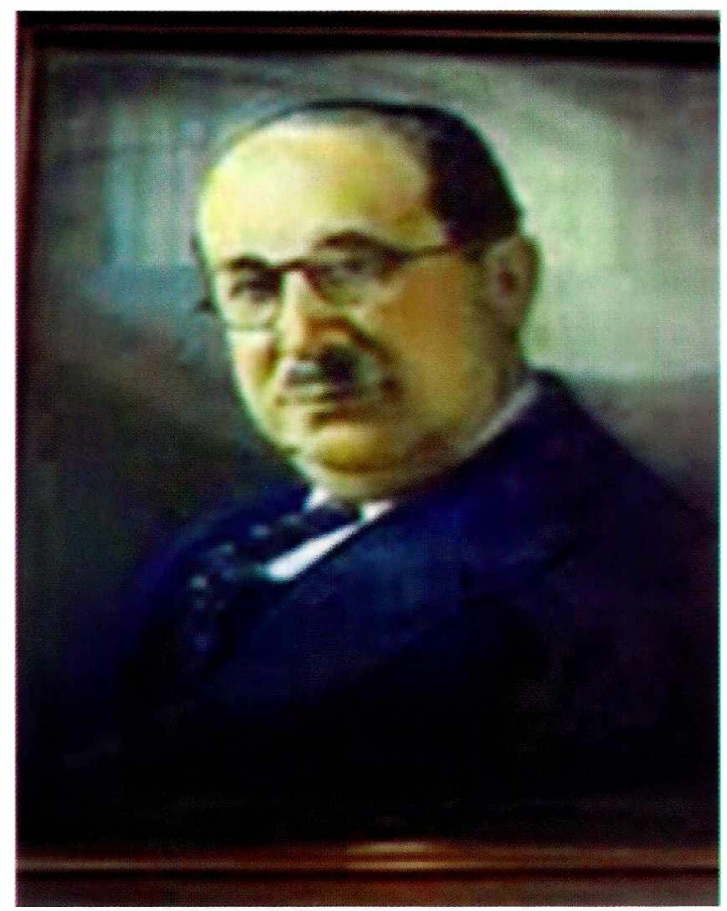

Figura 6. Dr. Lisandro Leyva Pererira. 
El mismo doctor Leiva como presidente de la Sociedad de Cirugía en una de sus sesiones reconoció el progreso científico de la anestesia en el Hospital de San José, impulsado por los doctores Santiago Triana Cortes y Carlos Tirado Macías. Hasta 1938 los anestesiólogos disponían de cloroformo, éter y oxido nitroso, (Figura 7) después aparece el ciclopropano que desplaza al cloroformo. Las anestesias se complementan con morfina y escopolamina, en especial esta última para la premedicación que apenas se iniciaba. Como fármacos locales para las anestesias regionales se contaba con cocaína, estovaína, novocaína y scurocaína

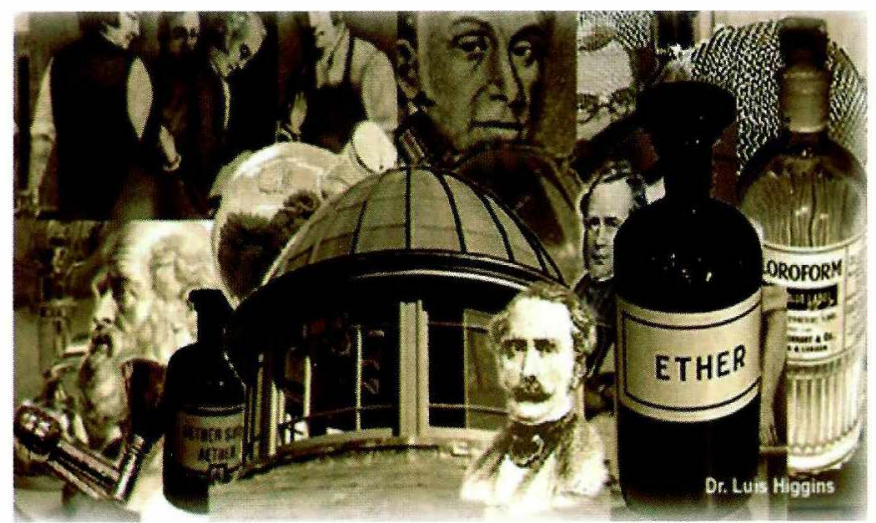

Figura 7. Anestésicos usados hasta 1938.

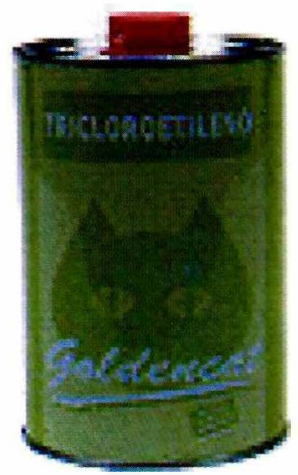

Figura 8. Tricloroetileno usado hasta 1963.

Luego llegarían el pentotal sódico y el curare que persistieron por largo tiempo. Más tarde se inicia el uso del trilene (tricloro-etileno) (Figura 8), el cual se suministraba con un dispensador especial que se ajustaba a la muñeca de la parturienta hasta llegar al estado de semi-inconsciencia y con este se atendían partos, ver- siones internas, fórceps, etc., con no pocos accidentes desafortunados. Este anestésico se usó hasta 1963.

En 1945, fue nombrado como jefe de Anestesia en el Hospital San José el doctor Juan Marín Osorio (Figura 9) y con él se inició la era docente de la anestesiología y la formación de la especialidad. Fue el verdadero gestor de esta apasionante disciplina cuyos primeros pasos los dió con la hermana Hermelinda (Figura 10) de la Comunidad de la Presentación de Tours, quien trabajó por más de 50 años en el hospital de la Misericordia. Antes del doctor Marín las anestesias las daban las monjas y algunos estudiantes.

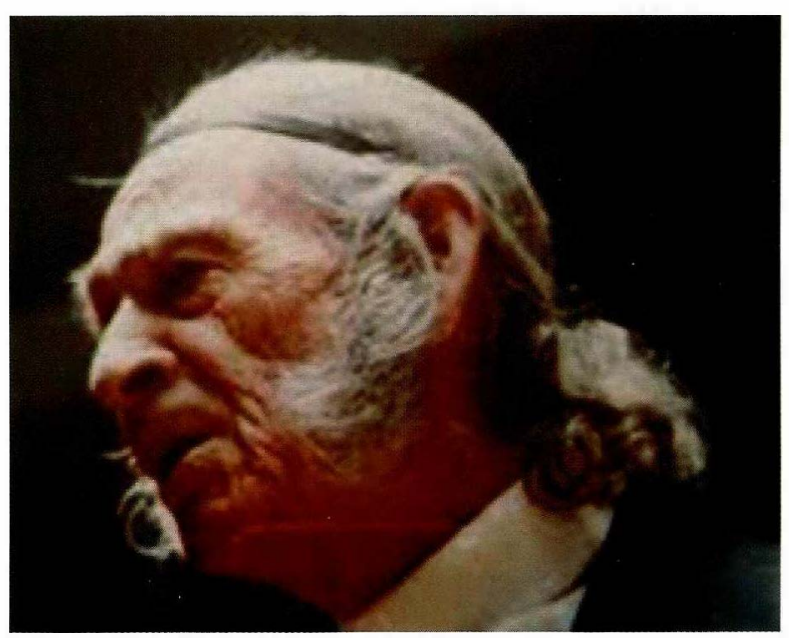

Figura 9. Dr. Juan Marín Osorio.

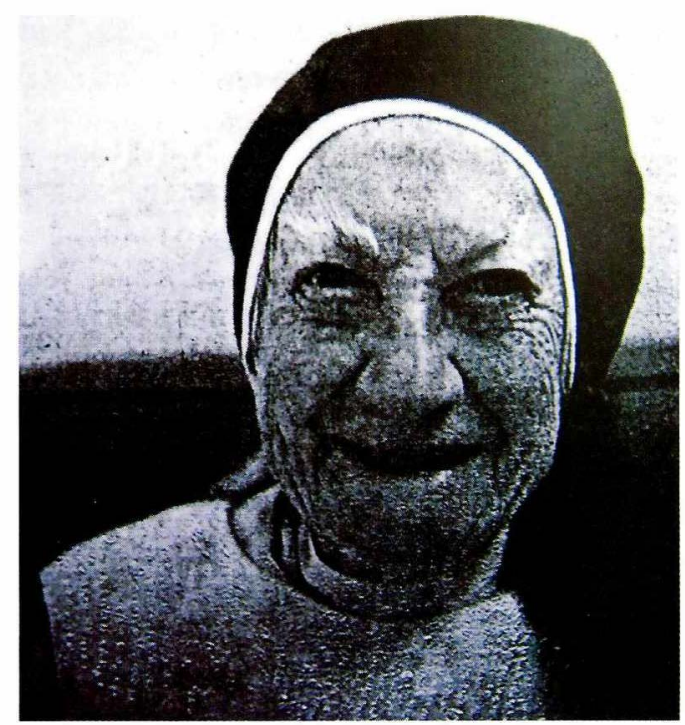

Figura I0. Hermana Hermelinda. 
El inició la primera escuela en el hospital San José en 1947, siendo esta pionera en Colombia. La apertura del curso se hizo con seis señoritas hijas de médicos del hospital; a este primer llamado no concurrieron estudiantes ni internos, se graduaron tres promociones en 1947, en 1948 y 1949; al segundo curso ingreso por primera vez un estudiante, Armando McCormick.

La fundación de la Sociedad Colombiana de Anestesiología (SCARE) se realizó el 23 de septiembre de 1949, en el salón Fundadores del hospital, como presidente transitorio se nombró al doctor Juan Marín, quien renunció y se le nombró secretario perpetuo (Figura 11). En 1940 llegó de Estados Unidos el doctor Juan Salamanca, siendo el primer anestesiólogo de escuela con que contó el país y reemplazo al doctor Marín en el hospital San José. En esta década fueron importantes tres anestesiólogos en Bogotá, Juan Salamanca en San José, Juan Marín en la Misericordia y Juan Martínez en Marly.

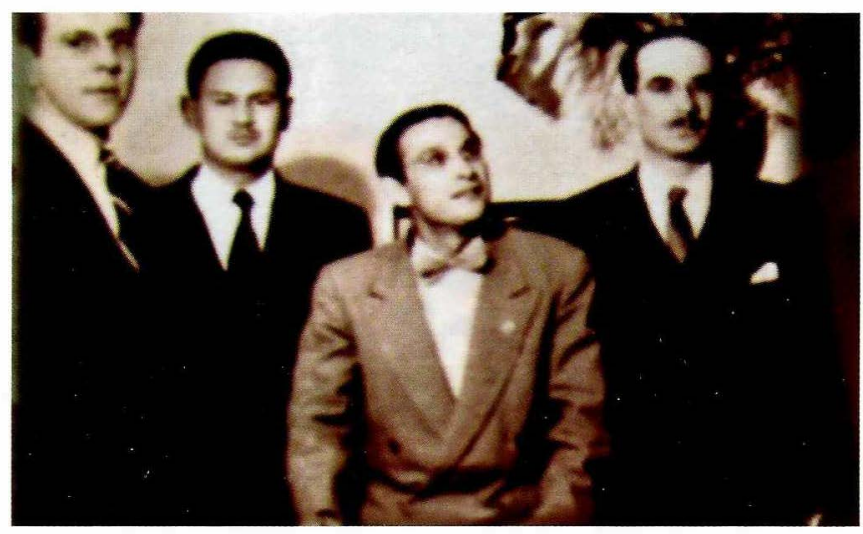

Figura I I. Fundación de la Sociedad Colombiana de Anestesiología (SCARE).

En el mes de octubre de 1950 llegó a San José una misión de norteamérica presidida por el doctor George Humphreys, e integrada por varios profesionales, entre ellos un anestesiólogo muy importante, el doctor Perry Volpitto (Figura 12) de la universidad de Georgia. Las recomendaciones fueron definitivas en el proceso de cambio de la escuela francesa, dominante hasta entonces, a la escuela norteamericana en lo docente y en lo asistencial.

En 1952 se realizó el primer Congreso Colombiano de Anestesiología cuya inauguración se llevó a cabo en el salón Fundadores del Hospital de San José el 26 de Agosto a las 7pm. Fue organizado por la Sociedad Colombiana de Anestesiología y patrocinado por la Sociedad de Cirugía de Bogotá. De 1950 a 1972 continuaron las labores asistenciales en el hospital sin hechos sobresalientes en anestesiología. Laboraron por esta época el doctor Uriel Álvarez y las técnicas Yolanda Chavarro, Beatriz Villaneda, Griselda Salas y Clara Hernández.

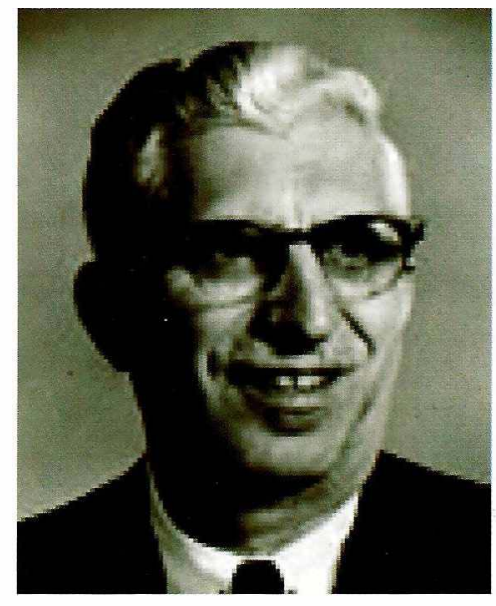

Figura 12. Dr. Perry P.Volpitto de la Universidad de Georgía (EUA).

En 1973 resurge el prestigio de la anestesiología en esta institución al ser nombrado en su jefatura el doctor Rafael Peña Castro (Figura 13) graduado en Argentina y que venía del Hospital Infantil y de la clínica David Restrepo de Bogotá; el doctor Peña era un hombre estudioso, trabajador y excelente organizador y le dió un giro total a la anestesia en el hospital, posicionándola entre las mejores del país; después de varios años se fue a trabajar a la clínica del Country de Bogotá.

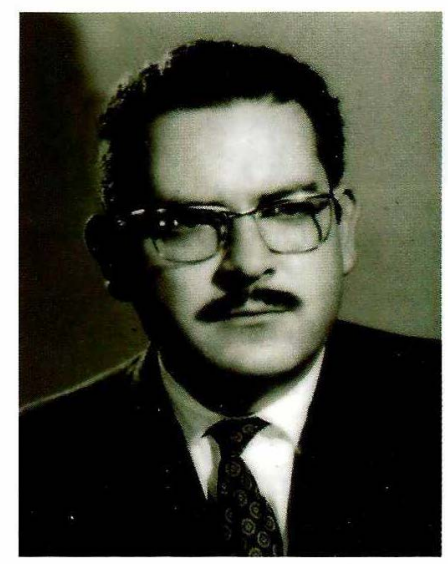

Figura I3. Dr. Rafael Peña. 
El doctor Eduardo García (Figura 14) trabajó durante tres años en el Hospital de San José en anestesia cardiovascular, luego se trasladó a la Samaritana y después a la Fundación Santa Fe siendo reemplazado por el doctor Carlos Castellanos Ch. (Figura 15), quien desempeño el cargo en anestesia cardiovascular durante 18 años y en la actualidad permanece en el servicio.

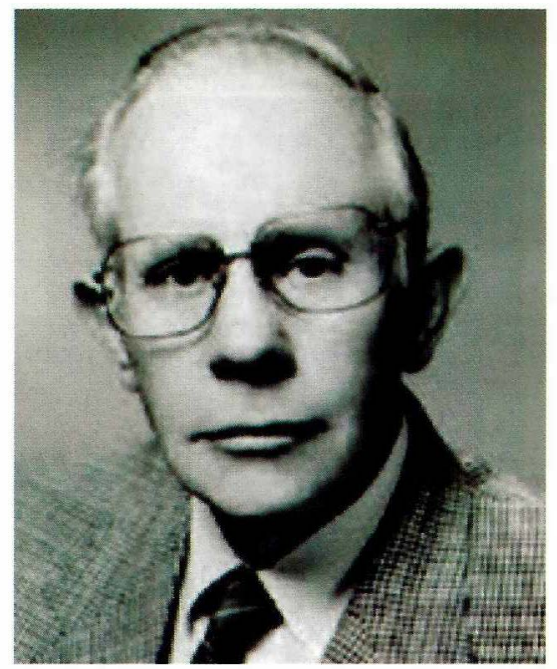

Figura I4. Dr. Eduardo García.

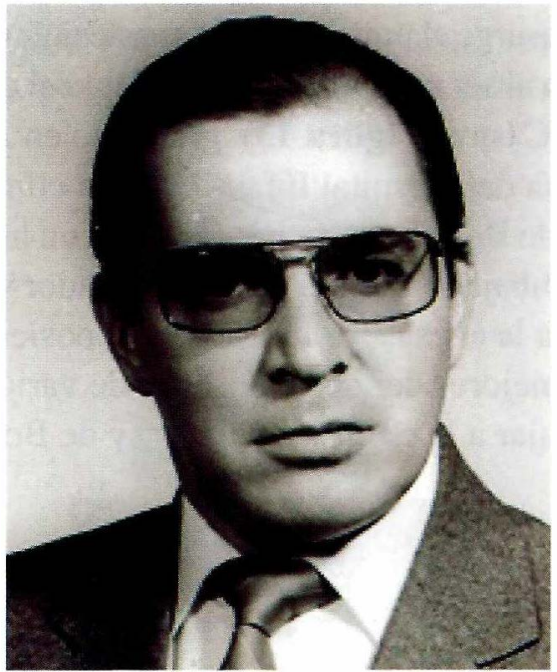

Figura I5. Dr. Carlos Castellanos.

La jefatura del Servicio de anestesia ha sido desempeñada sucesivamente por los doctores Alfonso Gómez, Luis Molinares, quien continúa en el servicio, Diego Londoño, Oscar Pinzón, Fernando Umaña, Stella Ortegón. Todos ellos han contribuido al crecimiento y mejoramiento de la especialidad. En la actualidad está a cargo del doctor Luis Eduardo Reyes quien inicia una etapa de reestructuración incorporando la sistematización, la investigación, la administración, la reorganización de la clínica del dolor y cuidados paliativos en un marco innovador docente asistencial. Merece un comentario especial la reorganización de la clínica del dolor y cuidados paliativos que iniciara el Dr. Aníbal Galindo (Figura 16) en 1.969, uno de los primeros en abordar esta disciplina en Colombia y que luego continuara el Dr. Manuel Palacios y sus colaboradores, labor que fructifica hoy con el surgimiento del centro interdisciplinario de medicina del dolor y cuidados paliativos del Hospital de San José, dirigido por el doctor Luis Alberto Garzón, con el respaldo académico de la Fundación Universitaria de Ciencias de la Salud (FUCS).

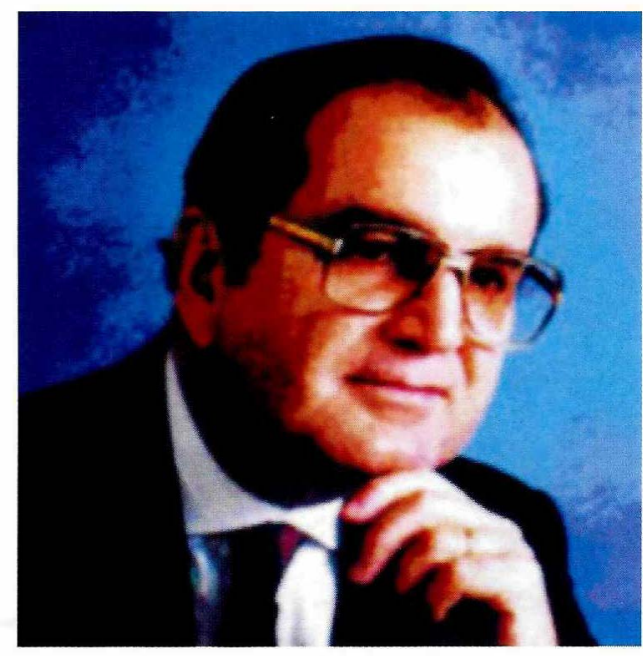

Figura I6. Dr.Anibal Galindo

La escuela de anestesia del Hospital de San José sigue siendo una de las primeras de la especialidad en el país y sus metas marchan a la par con los avances de la ciencia y la tecnología que se suscitan en el mundo actual, asumiendo los retos en la prestación de servicios y en la docencia con ética, eficiencia, profesionalismo y seguridad.

\section{Lecturas recomendadas}

Castellanos Ch. Carlos: Orígenes de la Anestesiología en Bogotá. Memorias Curso Anual 2.007 S.C.A. (Sociedad Cundinamarquesa de Anestesiología) Pág. 58-64 Herrera Pontón Jaime: Historia de la Anestesia en Colombia 1.999, Gente Nueva Editorial.

Muñoz Laurentino: Historia del Hospital de San José 1.902-1956. Bogotá 1.958. Imprenta del Banco de la Republica. 